This item was submitted to Loughborough's Research Repository by the author.

Items in Figshare are protected by copyright, with all rights reserved, unless otherwise indicated.

\title{
An automotive engine charge-air intake conditioner system: thermodynamic analysis of performance characteristics
}

PLEASE CITE THE PUBLISHED VERSION

PUBLISHER

Professional Engineering Publishing / @ IMECHE

VERSION

VoR (Version of Record)

\section{LICENCE}

CC BY-NC-ND 4.0

\section{REPOSITORY RECORD}

Taitt, D.W., Colin P. Garner, E. Swain, M.D. Bassett, R.J. Pearson, and J.W.G. Turner. 2019. "An Automotive Engine Charge-air Intake Conditioner System: Thermodynamic Analysis of Performance Characteristics". figshare. https://hdl.handle.net/2134/4831. 
This item was submitted to Loughborough's Institutional Repository (https://dspace.lboro.ac.uk/) by the author and is made available under the following Creative Commons Licence conditions.

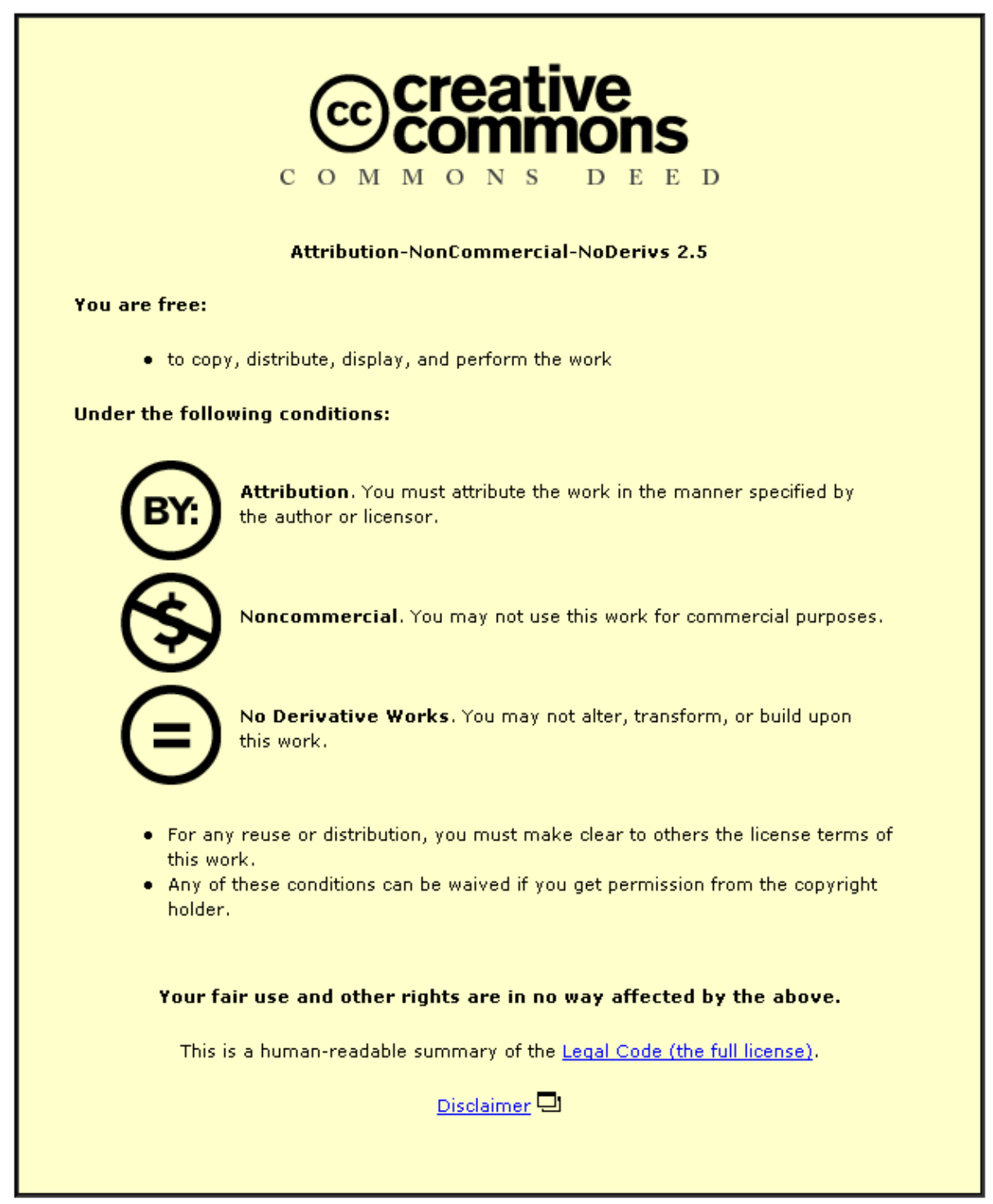

For the full text of this licence, please go to: http://creativecommons.org/licenses/by-nc-nd/2.5/ 


\title{
An automotive engine charge-air intake conditioner system: thermodynamic analysis of performance characteristics
}

\author{
D W Taitt ${ }^{1}$, C P Garner ${ }^{1}$, E Swain ${ }^{1 *}$, M D Bassett ${ }^{2}$, R J Pearson ${ }^{2}$, and J W G Turner ${ }^{2}$ \\ ${ }^{1}$ Wolfson School of Mechanical and Manufacturing Engineering, Loughborough University, Loughborough, UK \\ ${ }^{2}$ Group Lotus plc, Norwich, UK
}

The manuscript was received on 21 June 2004 and was accepted after revision for publication on 6 September 2004.

DOI: $10.1243 / 095440705 X 6587$

\begin{abstract}
A first law thermodynamic model has been developed and used to characterize the performance of an automotive engine charge-air intake conditioner system. This system employs a compressor, intercooler, and expander to provide increased charge density with the possibility of reducing, the charge-air temperature below the sink temperature. The model was validated against experimental measurements. The variation of system effectiveness with compressor, intercooler, and expander efficiency was quantified and system operating limits were identified. While the expander was found to have a greater effect than the compressor, the performance of the system was shown to be most dependent upon intercooler effectiveness.
\end{abstract}

Keywords: internal combustion engine, pressure charging, intercooling, charge-air temperature, expander

\section{INTRODUCTION}

\subsection{Fuel economy, downsizing, and pressure charging}

Environmental and economic concerns associated with the dependence of the global economy upon petroleum fuels have raised the importance of fuel economy both as a legislated driver and market driver of engine technology. The combination of engine downsizing and intake pressure charging is particularly applicable to throttled spark ignition (SI) engines. It results in the engine running at a higher brake mean effective pressure (b.m.e.p.) for a given road-load, with corresponding reductions in pumping losses and improvements in brake specific fuel consumption (b.s.f.c.).

The full fuel economy benefits of this approach are, however, rarely realized since the full load requirement for knock-free combustion (with pressure charging) demands that the engine compression ratio be reduced. Typically, a boost pressure of $100 \mathrm{kPa}$

\footnotetext{
* Corresponding author: Wolfson School of Mechanical and Manufacturing Engineering, Loughborough University, Loughborough, Leicestershire, LE11 3TU, UK. email: e.swain@lboro.ac.uk
}

(gauge) requires a compression ratio of around 8.0:1 [1] compared with a value of around 10:1 for a typical naturally aspirated engine. This reduction in compression ratio leads to a loss of engine thermodynamic efficiency throughout the speed and load range, with a consequent increase in fuel consumption.

One method of recovering engine thermodynamic efficiency is to increase the compression ratio under suitable operating conditions. The SAAB SVC engine [2], for example, operates at compression ratios as low as 8:1 at full load and as high as 14:1 at part load. The quoted improvements in b.s.f.c. and fuel economy are as much as 25 per cent. The mechanism to change compression ratio is, however, complex and presents significant challenges in terms of reliability, weight, and cost.

An alternative approach involves finding a way of achieving knock-free full-load combustion while maintaining a high (fixed) compression ratio. The propensity for knock to occur is a function of, among other factors, cylinder end-gas temperature and pressure [3], which are, in turn, functions of charge temperature and pressure at the start of compression. In the case of pressure charged engines, the most widely used method of reducing the start of 
compression temperature is intercooling. However, the performance of the intercooler, and thus the extent of the charge-air temperature reduction, is limited by the temperature of the sink to which the heat is rejected and the effectiveness of the intercooler itself. With such a system it is not possible to reduce charge-air temperature below the sink temperature.

In this paper, an alternative approach to achieving engine downsizing together with good fuel economy, using an engine charge-air intake conditioner system, is considered.

\subsection{Charge-air intake conditioner system}

A charge-air intake conditioner system has been proposed [4] that provides both increased charge density and the possibility of reducing the charge-air temperature below the sink temperature. This system, shown in schematic form in Fig. 1, differs from a conventional system by expanding the intake air after the intercooler to achieve a further reduction in temperature and pressure, along with a corresponding recovery of work.

The principle of operation is illustrated on the temperature-entropy $(T-s)$ diagram in Fig. 2. Points 1 to $4^{\prime}$ represent the ideal process. Air is compressed isentropically from points 1 to 2 '. (The charge-air pressure at point $2^{\prime}$ is necessarily higher than the engine inlet pressure at point $4^{\prime}$.) Heat is rejected at constant pressure to point 3 ', from where it is expanded isentropically to the desired engine inlet conditions at point 4 '. In reality, both compression and expansion will be accompanied by an increase in entropy and the heat rejection process will incur a flow-related pressure loss. The real process is represented by points 1 to 4 . This process, upon which the present system is based, clearly has a number of attractive features that include:

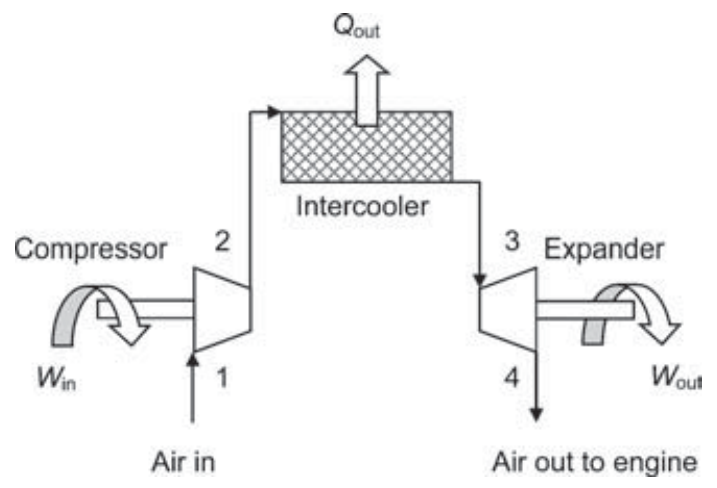

Fig. 1 Schematic of the charge-air intake conditioner system

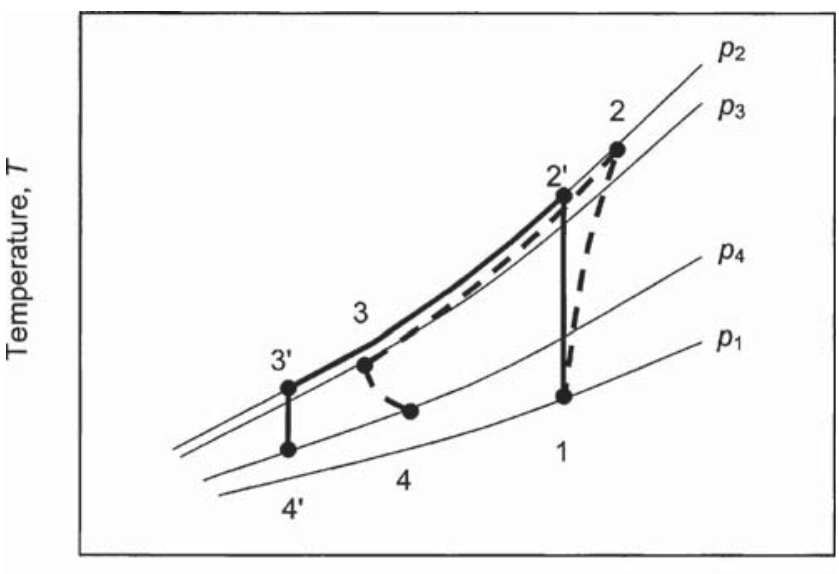

Specific entropy, $s$

Fig. 2 Generic $T-s$ diagram for the charge-air intake conditioner system

1. Charge-air temperature reduction is no longer limited by the performance of the intercooler and may be cooled below the sink temperature.

2. Careful control of the system allows constant charge-air density to be maintained across a range of temperatures and pressures (high temperature, high pressure or low temperature, low pressure).

The compressor requires work input and the expander generates a work output; the system as a whole requires a net work input. For an automotive application, this net work requirement of the system must be met by the engine itself. Work may be delivered to the compressor from the crankshaft by means of direct drives, including the shaft, belt, or gear. Another possible form of drive is an exhaust gas driven turbine. Alternatively, an indirect drive method such as an electric motor may be used. The expander work output may contribute to the compressor work requirement by a direct coupling. Alternatively, the expander work may be delivered back to the crankshaft by means of a direct coupling or indirectly through an electrical generator. Figure 3 shows the system proposed by Turner et al. [4], which uses an exhaust gas driven turbine to drive the compressor and a positive displacement screw expander with a direct drive to the crankshaft.

\section{ANALYSIS OBJECTIVES}

Recent work [4] has identified the potential benefits of a charge-air intake conditioner system. While the feasibility of such a system has been demonstrated on a rig, a full analysis has yet to be conducted. 


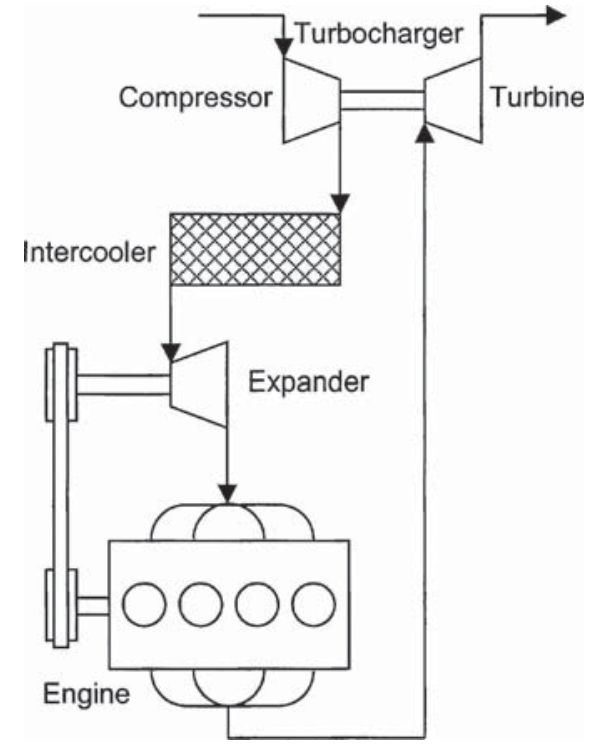

Fig. 3 Charge-air intake conditioner system as proposed by Turner et al. [4]

The new work in this paper therefore addresses stage 1 of a full system analysis, which comprises:

Stage 1. Charge-air intake conditioner system modelling to determine charge-air temperature and work input requirement as a function of system performance parameters, at constant charge-air density and mass flowrate.

Stage 2. Engine cycle simulation to determine chargeair temperature and charge-air conditioner work input requirement at constant full-load b.m.e.p.

Stage 3. Combustion modelling to determine the knock-limited compression ratio as a function of charge-air temperature.

Stage 4. Engine cycle simulation to determine the b.s.f.c. map as a function of the knock-limited compression ratio. Vehicle performance simulation to determine the corresponding in-vehicle fuel economy.

The objective of this paper is to document the analysis to characterize the performance of the charge-air intake conditioner system alone by means of a first law thermodynamic analysis. This is the first in a series of analyses that will ultimately characterize fuel economy as a function of system performance parameters (i.e. compressor, intercooler, and expander efficiencies).

The value of performing this stand-alone analysis is that it provides an early assessment of the feasibility of a particular system specification. The $T-S$ diagram in Fig. 2 shows that the individual component efficiencies can have a significant effect on the performance of the system as a whole. It therefore follows that there are necessarily critical limits beyond which the system may require an unacceptable work input or indeed may, under some circumstances, be incapable of providing any temperature reduction at all. In such cases there is clearly no need or value to go on to the subsequent stages in the full analysis and hence time and effort can be saved.

It is particularly appropriate to use a first law thermodynamic approach. It derives speed from its computerized simplicity, versatility from the generic nature of its input, and immediate relevance by virtue of its numerical output: specifically, the charge-air temperature and work input requirement.

The following sections of this paper detail the theoretical basis and validation of the model and the analytical approach, results, and conclusions from the study.

\section{CHARGE-AIR CONDITIONER SYSTEM MODEL}

\subsection{Control volumes}

The system was modelled as shown in Fig. 4. The first law thermodynamic model developed here comprised three control volumes: compressor, intercooler, and expander. These components were specified by compressor isentropic efficiency, intercooler effectiveness, and expander isentropic efficiency respectively. The model does not require assumptions about the type of device used (e.g. centrifugal or positive displacement) and is therefore generic. The components were connected by pipes of defined, common crosssectional area, to allow the determination of mean flow velocities.

\subsection{Steady flow energy equation}

The model used the steady flow energy equation (SFEE)

$$
\dot{E}_{\text {in }}-\dot{E}_{\text {out }}=\Delta \dot{E}_{\text {sys }}=0
$$

It should be noted that throughout this paper the subscripts 'in' and 'out' are used to indicate the direction of flow and thus a formal sign convention is not required.

Enthalpy and kinetic energy terms were included in the analysis but potential energy terms were neglected since their differences were small. Both compressor and expander were modelled as adiabatic 


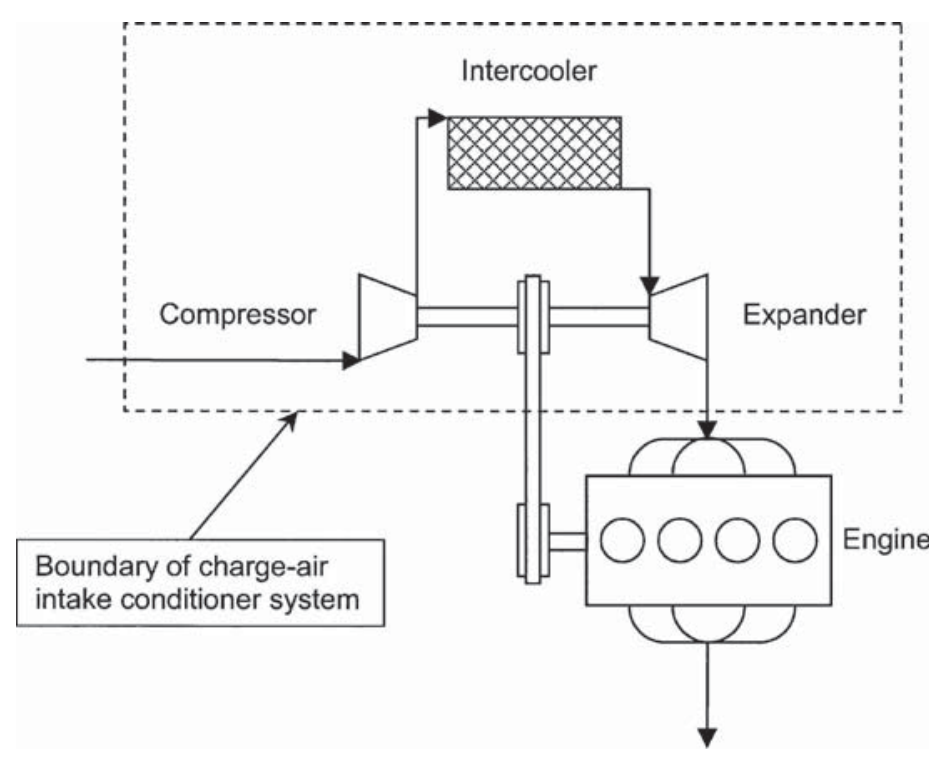

Fig. 4 Simplified charge-air intake conditioner system as modelled thermodynamically

devices; with no intentional cooling, heat transfer would be small relative to the shaft work [5].

\subsubsection{Compressor}

Application of the SFEE in equation (1) to the compressor gives

$$
\dot{W}_{\text {in }}+\dot{m}_{\text {in }}\left(h_{\text {in }}+\frac{1}{2} v_{\text {in }}^{2}\right)-\dot{m}_{\text {out }}\left(h_{\text {out }}+\frac{1}{2} v_{\text {out }}^{2}\right)=0
$$

and using mass conservation for a single inlet and outlet

$$
\dot{m}_{\text {out }}=\dot{m}_{\text {in }}=\dot{m}
$$

Equation (2) can be rearranged as

$$
\dot{W}_{\text {in }}=\dot{m}\left[h_{\text {out }}-h_{\text {in }}+\frac{1}{2}\left(v_{\text {out }}^{2}-v_{\text {in }}^{2}\right)\right]
$$

or

$$
w_{\text {in }}=h_{\text {out }}-h_{\text {in }}+\frac{1}{2}\left(v_{\text {out }}^{2}-v_{\text {in }}^{2}\right)
$$

where

$$
w=\frac{\dot{W}}{\dot{m}}
$$

For an ideal gas with variable specific heats

$$
\mathrm{d} h=c_{p}(T) \mathrm{d} T
$$

Integrating equation (7) and substituting into equation (5) gives an expression for the compressor specific work input

$$
w_{\text {in }}=\int_{\text {in }}^{\text {out }} c_{p}(T) \mathrm{d} T+\frac{1}{2}\left(v_{\text {out }}^{2}-v_{\text {in }}^{2}\right)
$$

\subsubsection{Intercooler}

For the intercooler there are no work interactions and the SFEE [equation (1)] gives

$$
\dot{m}_{\text {in }}\left(h_{\text {in }}+\frac{1}{2} v_{\text {in }}^{2}\right)-\dot{Q}_{\text {out }}-\dot{m}_{\text {out }}\left(h_{\text {out }}+\frac{1}{2} v_{\text {out }}^{2}\right)=0
$$

Rearranging equation (9) gives

$$
\dot{Q}_{\text {out }}=\dot{m}\left[h_{\text {in }}-h_{\text {out }}+\frac{1}{2}\left(v_{\text {in }}^{2}-v_{\text {out }}^{2}\right)\right]
$$

or

$$
q_{\text {out }}=h_{\text {in }}-h_{\text {out }}+\frac{1}{2}\left(v_{\text {in }}^{2}-v_{\text {out }}^{2}\right)
$$

where

$$
q=\frac{\dot{Q}}{\dot{m}}
$$

Integration of equation (7) and substitution in equation (11) results in an expression for the intercooler specific heat rejection

$$
q_{\text {out }}=\int_{\text {out }}^{\text {in }} c_{p}(T) \mathrm{d} T+\frac{1}{2}\left(v_{\text {in }}^{2}-v_{\text {out }}^{2}\right)
$$

\subsubsection{Expander}

The SFEE [equation (1)] is applied to the expander

$$
\dot{m}_{\text {in }}\left(h_{\text {in }}+\frac{1}{2} v_{\text {in }}^{2}\right)-\dot{W}_{\text {out }}-\dot{m}_{\text {out }}\left(h_{\text {out }}+\frac{1}{2} v_{\text {out }}^{2}\right)=0
$$


Rearranging equation (14) and substituting into equation (6) gives

$$
w_{\text {out }}=h_{\text {in }}-h_{\text {out }}+\frac{1}{2}\left(v_{\text {in }}^{2}-v_{\text {out }}^{2}\right)
$$

Substituting the integral form of equation (7) gives an expression for the expander specific work output

$$
w_{\text {out }}=\int_{\text {out }}^{\text {in }} c_{p}(T) \mathrm{d} T+\frac{1}{2}\left(v_{\text {in }}^{2}-v_{\text {out }}^{2}\right)
$$

\subsection{Properties}

\subsubsection{Isentropic relations of ideal gases and the ideal gas equation of state}

Temperature and pressure were derived from the isentropic relation for ideal gases

$$
\frac{T}{p^{(\gamma-1) / \gamma}}=\text { constant }
$$

Density was derived using the ideal gas equation of state

$$
\rho=\frac{p}{R T}
$$

The working fluid (air) was treated as a semiperfect gas since its operating temperature range of $240-440 \mathrm{~K}$ was well above the critical temperature of $132.5 \mathrm{~K}$ and its operating pressure range of 96 to $1.146 \times 10^{6} \mathrm{~Pa}$ was well below the critical pressure of $3.77 \times 10^{6} \mathrm{~Pa}[\mathbf{5}]$.

\subsubsection{Specific heat capacity}

The variation of specific heat capacity $c_{p}$ with temperature $T$ was accommodated in the form of a third-order polynomial function [5]

$$
c_{p}=\frac{a_{\mathrm{I}}+a_{\mathrm{II}} T+a_{\mathrm{III}} T^{2}+a_{\mathrm{IV}} T^{3}}{M}
$$

This function is valid in the temperature range 273-1800 K with a maximum error of 1.01 per cent and an average error of 0.26 per cent.

For improved accuracy, the analysis used integral, rather than average, values across temperature differences. Generally, the integral value of $c_{p}$ between any two temperatures, $T_{\text {in }}$ and $T_{\text {out }}$, is denoted $c_{p_{\text {in-out }}}$ and is defined as

$$
c_{p_{\text {in-out }}}=\frac{\int_{\text {in }}^{\text {out }} c_{p}(T) \mathrm{d} T}{T_{\text {out }}-T_{\text {in }}}
$$

Integrating the polynomial expression for $c_{p}$ gives

$$
c_{p_{\text {in }- \text { out }}}=\frac{\begin{array}{c}
a_{\mathrm{I}}\left(T_{\text {out }}-T_{\text {in }}\right)+\frac{1}{2} a_{\text {II }}\left(T_{\text {out }}^{2}-T_{\text {in }}^{2}\right) \\
+\frac{1}{3} a_{\text {III }}\left(T_{\text {out }}^{3}-T_{\text {in }}^{3}\right)+\frac{1}{4} a_{\mathrm{IV}}\left(T_{\text {out }}^{4}-T_{\text {in }}^{4}\right)
\end{array}}{M\left(T_{\text {out }}-T_{\text {in }}\right)}
$$

The integral value of $\gamma$ between any two temperatures, $T_{\text {in }}$ and $T_{\text {out }}$, is denoted $\gamma_{\text {in-out }}$ and is defined as

$$
\gamma_{\text {in-out }}=\frac{c_{p_{\text {in-out }}}}{c_{p_{\text {in-out }}}-R}
$$

\subsubsection{Compressor inlet properties}

Compressor inlet static conditions were derived from atmospheric pressure $p_{\text {atm }}$, temperature $T_{\text {atm }}$, air mass flowrate $\dot{m}$, and flow area $A$. An isentropic compressor inlet was assumed. Thus

$$
\begin{aligned}
& T_{01}=T_{\text {atm }} \\
& p_{01}=p_{\text {atm }}
\end{aligned}
$$

Compressor inlet static temperature was determined from the relationship

$$
T_{1}=\frac{c_{p_{01}}}{c_{p_{1}}} T_{01}-\frac{v_{1}^{2}}{2 c_{p_{1}}}
$$

The compressor inlet velocity was calculated using the continuity equation

$$
v_{1}=\frac{\dot{m}}{\rho_{1} A}
$$

and compressor inlet density was derived from the ideal gas equation of state

$$
\rho_{1}=\frac{p_{1}}{R T_{1}}
$$

Compressor inlet static pressure was calculated from equation (17)

$$
p_{1}=p_{01}\left(\frac{T_{1}}{T_{01}}\right)^{\gamma_{01-1} /\left(\gamma_{01-1}-1\right)}
$$

and equation (22) was used to derive the ratio of specific heats

$$
\gamma_{01-1}=\frac{c_{p_{01-1}}}{c_{p_{01-1}}-R}
$$

The solution of these equations involved iteration around $T_{1}$ and integration of the third-order polynomial function, $c_{p}=c_{p}(T)$, between $T_{01}$ and $T_{1}$. 


\subsubsection{Compressor outlet properties}

The compressor pressure ratio (static to static) $r_{\text {comp }}$ is defined as

$$
r_{\text {comp }}=\frac{p_{2}}{p_{1}}
$$

and was used to determine the ideal compressor outlet temperature $T_{2 \mathrm{i}}$ for an isentropic compression process using an integral value of $\gamma$ between $T_{1}$ and $T_{2 \mathrm{i}}$

$$
T_{2 \mathrm{i}}=T_{1} r_{\text {comp }}^{\left(\gamma_{1-2 \mathrm{i}}-1\right) / \gamma_{1-2 \mathrm{i}}}
$$

The actual compressor outlet temperature $T_{2}$ was then calculated using the compressor isentropic efficiency $\eta_{\text {comp }}$, which is defined as

$$
\eta_{\text {comp }}=\frac{w_{\mathrm{i}}}{w_{\mathrm{a}}}=\frac{h_{02 \mathrm{i}}-h_{01}}{h_{02}-h_{01}}
$$

where

$$
w=\frac{\dot{W}}{\dot{m}}
$$

Application of the SFEE in the form of equation (8) gives

$$
\eta_{\text {comp }}=\frac{\int_{1}^{2 \mathrm{i}} c_{p}(T) \mathrm{d} T+\frac{1}{2}\left(v_{2 \mathrm{i}}^{2}-v_{1}^{2}\right)}{\int_{1}^{2} c_{p}(T) \mathrm{d} T+\frac{1}{2}\left(v_{2}^{2}-v_{1}^{2}\right)}
$$

Substituting equation (20) in both the numerator and denominator of equation (34) gives

$$
\eta_{\text {comp }}=\frac{c_{p_{1-2 \mathrm{i}}}\left(T_{2 \mathrm{i}}-T_{1}\right)+\frac{1}{2}\left(v_{2 \mathrm{i}}^{2}-v_{1}^{2}\right)}{c_{p_{1-2}}\left(T_{2}-T_{1}\right)+\frac{1}{2}\left(v_{2}^{2}-v_{1}^{2}\right)}
$$

which was rearranged to give an expression for the actual charge-air temperature at the compressor outlet

$$
\begin{aligned}
T_{2}= & T_{1}+\frac{1}{\eta_{\text {comp }}} \frac{c_{p_{1-2 \mathrm{i}}}}{c_{p_{1-2}}}\left(T_{2 \mathrm{i}}-T_{1}\right) \\
& +\frac{1}{2 c_{p_{1-2}}}\left[\frac{1}{\eta_{\text {comp }}}\left(v_{2 \mathrm{i}}^{2}-v_{1}^{2}\right)-\left(v_{2}^{2}-v_{1}^{2}\right)\right]
\end{aligned}
$$

\subsubsection{Intercooler outlet properties}

A generic intercooler was modelled with a sink temperature, $T_{\text {sink }}$. The intercooler outlet temperature $T_{3}$ was calculated using intercooler effectiveness $E_{\mathrm{IC}}$, which is defined as

$$
E_{\mathrm{IC}}=\frac{T_{2}-T_{3}}{T_{2}-T_{\text {sink }}}
$$

$T_{\text {sink }}$ was taken to be the ambient atmospheric temperature, $T_{\text {atm }}$, and hence

$$
T_{3}=T_{2}\left(1-E_{\mathrm{IC}}\right)+T_{\mathrm{atm}} E_{\mathrm{IC}}
$$

The static pressure drop across the intercooler $\Delta p_{\text {IC }}$ was modelled as being proportional to the intercooler inlet density and the square of the intercooler inlet velocity. Thus

$$
\Delta p_{\text {IC }}=\frac{1}{2} k \rho_{2} v_{2}^{2}
$$

where $k$ is an empirical intercooler pressure drop constant derived using reference values from measured data $[4]$

$$
\begin{aligned}
& \Delta p_{\mathrm{IC}_{\mathrm{ref}}}=19 \times 10^{3} \mathrm{~Pa} \\
& \rho_{2_{\text {ref }}}=2.32 \mathrm{~kg} / \mathrm{m}^{3} \\
& v_{2_{\text {ref }}}=48.48 \mathrm{~m} / \mathrm{s}
\end{aligned}
$$

The intercooler outlet pressure was determined from

$$
p_{3}=p_{2}-\Delta p_{\text {IC }}
$$

\subsubsection{Expander outlet properties}

The expander pressure ratio (static to static) is defined as

$$
r_{\mathrm{ex}}=\frac{p_{4}}{p_{3}}
$$

and the ideal expander outlet temperature was then calculated for an isentropic expansion process using an integral value of $\gamma$ between $T_{3}$ and $T_{4 \mathrm{i}}$

$$
T_{4 \mathrm{i}}=T_{3} r_{\mathrm{ex}}^{\left(\gamma_{3}-4 \mathrm{i}-1\right) / \gamma_{3-4 \mathrm{i}}}
$$

The actual expander outlet temperature $T_{4}$ was calculated using the expander isentropic efficiency $\eta_{\mathrm{ex}}$, which is defined as

$$
\eta_{\mathrm{ex}}=\frac{w_{\mathrm{a}}}{w_{\mathrm{i}}}=\frac{h_{03}-h_{04}}{h_{03}-h_{04 \mathrm{i}}}
$$

Application of the SFEE in the form of equation (16) gives

$$
\eta_{\mathrm{ex}}=\frac{\int_{4}^{3} c_{p}(T) \mathrm{d} T+\frac{1}{2}\left(v_{3}^{2}-v_{4}^{2}\right)}{\int_{4 \mathrm{i}}^{3} c_{p}(T) \mathrm{d} T+\frac{1}{2}\left(v_{3}^{2}-v_{4 \mathrm{i}}^{2}\right)}
$$

Substituting equation (20) in both the numerator and denominator of equation (44) gives

$$
\eta_{\mathrm{ex}}=\frac{c_{p_{3-4}}\left(T_{3}-T_{4}\right)+\frac{1}{2}\left(v_{3}^{2}-v_{4}^{2}\right)}{c_{p_{3-4 \mathrm{i}}}\left(T_{3}-T_{4 \mathrm{i}}\right)+\frac{1}{2}\left(v_{3}^{2}-v_{4 \mathrm{i}}^{2}\right)}
$$


from which the expander outlet temperature, $T_{4}$, was then derived as

$$
\begin{aligned}
T_{4}= & T_{3}-\eta_{\mathrm{ex}} \frac{c_{p_{3-4 \mathrm{i}}}}{c_{p_{3-4}}}\left(T_{3}-T_{4 \mathrm{i}}\right) \\
& +\frac{1}{2 c_{p_{3-4}}}\left[\left(v_{3}^{2}-v_{4}^{2}\right)-\eta_{\mathrm{ex}}\left(v_{3}^{2}-v_{4 \mathrm{i}}^{2}\right)\right]
\end{aligned}
$$

Since the expander analysis required constant outlet density $\rho_{4}$, the expander outlet pressure $p_{4}$ was calculated from the expander outlet density and temperature using the following expression of the ideal gas equation of state

$$
p_{4}=p_{4 \mathrm{i}}=p_{3} \frac{\rho_{4}}{\rho_{3}} \frac{T_{4}}{T_{3}}
$$

\section{MODEL VALIDATION}

The model was correlated against measured results from the work of Turner et al. [4]. A schematic diagram of the rig is shown in Fig. 5. The main components of the rig comprised a compressor, intercooler, and expander. Both compressor and expander were twin-screw positive displacement devices with internal compression and expansion respectively. The specifications of these devices are detailed in Table 1. The model used a generic intercooler with the cooling medium defined only by the sink temperature. Accordingly, the experimental intercooler was water-cooled, with modulation of the water flowrate to control intercooler performance. The rig was driven by a variable-speed electric motor with a primary belt drive to the compressor and a secondary belt drive between the compressor and

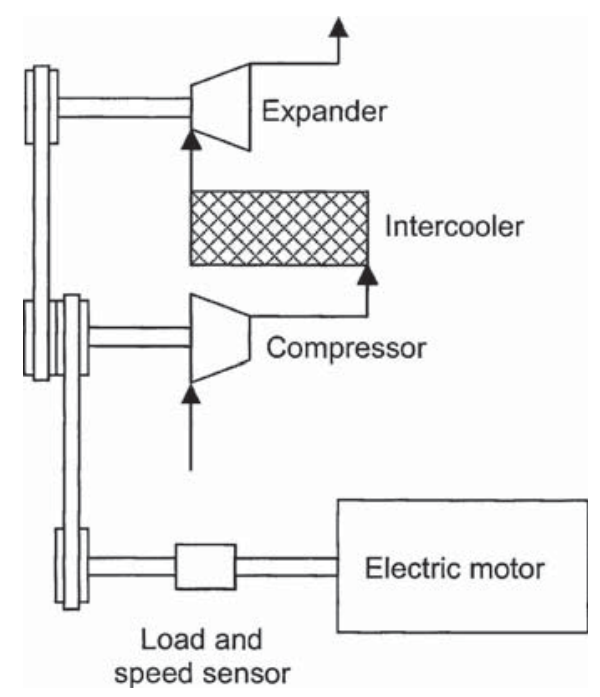

Fig. 5 Schematic of the experimental rig
Table 1 Specification of compressor and expander

\begin{tabular}{lll}
\hline & Compressor & Expander \\
\hline Type & Opcon OA 2087/2.3 & Opcon OA 1050/1.3 \\
Displacement & 0.87 litre/rev & 0.415 litre/rev \\
Internal pressure & $1: 2.3$ & $1.3: 1$ \\
$\quad$ ratio & & \\
\hline
\end{tabular}

the expander. An idling tensioner was used to control primary belt tension. A torque meter and speed sensor were installed between the motor and the primary belt drive to measure the net work input rate to the system.

Charge-air properties in the model were matched to those recorded from the rig and the calculated net work requirement was compared with the measured value. Figure 6 shows the correlation of calculated results with measured results across a range of work requirements. The model consistently and linearly underpredicts the net work requirement by approximately 7 per cent. A reasonable explanation for this discrepancy is that the rig measurements include friction work in the compressor, the expander, and the drive mechanism, which comprises two belts and an idling tensioner. Although the magnitudes of the associated friction losses were not available from the experimental work, it is reasonable to assume that they would account for a significant part, if not all, of the correlation discrepancy.

\section{ANALYTICAL APPROACH}

\subsection{Constants}

Ideally, the performance characteristics of the engine charge-air conditioner system would be evaluated at

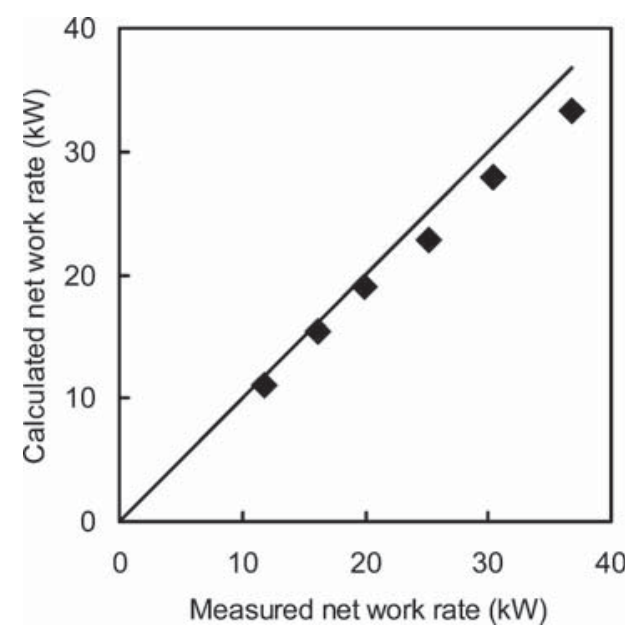

Fig. 6 Correlation of the model against the experimental results 
constant engine brake power output, and the most effective system would be that which achieved the required brake power output at the lowest chargeair temperature. This would require experimental work on a running engine or analysis using a cycle simulation code with a knock model. This full analysis will be the subject of future research. Here it is appropriate first to determine the performance characteristics of the charge-air conditioner system itself.

In this case, the performance of the charge-air conditioning system was analysed under conditions of constant charge-air density and constant charge-air mass flowrate (approximating to constant indicated engine power output). Atmospheric temperature and pressure were also held constant for the analysis, which modelled dry air. The values given in Table 2 were chosen to allow correlation with measured results.

\subsection{Performance criteria}

For the constant charge-air density and mass flowrate analysis it was necessary to choose some key parameters to define system performance.

\subsubsection{System effectiveness}

The objective of the charge-air conditioner system is to cool the engine intake air while maintaining charge density. The effectiveness of the system is therefore a function of the charge-air temperature, lower being better.

\subsubsection{Definition of efficiency and coefficient of performance (COP)}

The charge-air conditioner system has similarities with refrigeration systems in that both systems reduce temperature, but there are also important differences that preclude the determination of a corresponding coefficient of performance (COP) for the charge-air conditioner system. Both systems involve the compression and expansion of a fluid with heat transfer, but while refrigeration uses a separate refrigerant fluid (which undergoes two phase changes) in a closed circuit, the charge-air conditioner system has no refrigerant, as such, and the charge-air itself

Table 2 Constants

\begin{tabular}{ll}
\hline Parameter & Value \\
\hline Atmospheric temperature $T_{\text {atm }}$ & $302 \mathrm{~K}$ \\
Atmospheric pressure $P_{\text {atm }}$ & $1.013 \times 10^{6} \mathrm{~Pa}$ \\
Charge-air density $\rho_{4}$ & $2.378 \mathrm{~kg} / \mathrm{m}^{3}$ \\
Charge-air mass flowrate $\dot{m}$ & $0.225 \mathrm{~kg} / \mathrm{s}$ \\
\hline
\end{tabular}

undergoes an open-cycle process (with no phase changes). In the case of refrigeration, irreversible heat transfer alone reduces the temperature of the cooled fluid. For the charge-air conditioner there are two processes: irreversible heat transfer and adiabatic expansion. It is usual to express first law thermodynamic efficiency (or COP in the case of refrigeration) in terms of desired output and required input. For both systems the required input is work and the desired output from refrigeration is heat transfer from the system, allowing a COP to be determined in a straightforward manner. The desired output from the charge-air conditioner system is a low charge-air temperature; sharing neither the units nor the dimensions of work, this parameter cannot therefore be used to determine a non-dimensional COP. It is not appropriate to use heat transfer from the system as a measure of desired output since charge-air temperature reduction is also a function of adiabatic expansion and does not necessarily vary with heat transfer.

For these reasons, a particular function has not been chosen to quantify the efficiency or the COP of the charge-air conditioner system in a single value. Rather, a relative measure of efficiency was observed from the work input/charge-air temperature characteristic.

\subsection{Study variables}

The objective of the study was to characterize the performance of the charge-air conditioner system in terms of its sensitivity to the performance of its constituent parts. Table 3 identifies the system components with their respective performance parameters and the range of parameters studied in the analysis.

\subsection{Control variables}

These variables were used to set the level at which the charge-air conditioner system operated. Table 4 shows the control variables and the range of values

Table 3 Range of study variables

\begin{tabular}{lll}
\hline Component & Performance parameter & Range \\
\hline Compressor & Isentropic efficiency $\eta_{\text {comp }}$ & $0.5-1.0$ \\
Intercooler & Effectiveness $E_{\mathrm{IC}}$ & $0.6-1.0$ \\
Expander & Isentropic efficiency $\eta_{\mathrm{ex}}$ & $0.5-1.0$ \\
\hline
\end{tabular}

Table 4 Range of control variables

\begin{tabular}{ll}
\hline Control variable & Range \\
\hline Compressor pressure ratio $r_{\text {comp }}$ & $2.32-12.00$ \\
Expander pressure ratio $r_{\mathrm{ex}}$ & $1.00-11.17$ \\
\hline
\end{tabular}


used in the analysis. Having defined the specification of the system by the study variables, the compressor pressure ratio $r_{\text {comp }}$ was set to give a corresponding expander pressure ratio $r_{\text {ex }}$ of 1.0 at the required (constant) value of charge-air density at the expander outlet. This defined the starting point of the analysis, representing a conventional pressure-charged system with intercooling and no expander, and accounts for the non-integer value of $r_{\text {comp }}(=2.32)$ at the lower limit of its range in Table 4 . After this point the compressor pressure ratio was increased from 3.0 to 12.0 and the expansion ratio was increased accordingly to maintain constant charge-air density. The noninteger value of $r_{\mathrm{ex}}(=11.17)$ at the upper limit of its range in Table 4 corresponds to $r_{\text {comp }}=12$. It was necessary to establish the zero expansion point since this was used as the reference point from which the effectiveness of the system was determined as a function of the charge-air temperature drop. A maximum compressor pressure ratio of 12.0 was chosen solely for the purpose of displaying clearly the turning point and asymptotic performance characteristic effects. In order to maintain constant chargeair density it was necessary to adjust the expander pressure ratio with the compressor pressure ratio throughout the analysis.

\section{SYSTEM PERFORMANCE SENSITIVITY}

\subsection{Compressor effects}

Figure 7 shows the variation of net system work input rate with the charge-air temperature as a function of the compressor and expander pressure ratio for a range of compressor isentropic efficiencies between 0.5 and 1.0. In this case both intercooler effectiveness
$E_{\text {IC }}$ and expander isentropic efficiency $\eta_{\mathrm{ex}}$ were held constant at 0.6. The general characteristic is one of reducing the net system work input rate and charge-air temperature with increasing compressor isentropic efficiency. The shape and gradient of the curves are of particular interest. Curves that rise to the left, from their start point, demonstrate a system's potential for charge-air temperature reduction while those that rise to the right demonstrate a system's inability to reduce the charge-air temperature. Typically, a curve that rises to the left may, at some point, exhibit a minimum limit beyond which the charge-air temperature starts to rise again with increasing compressor pressure ratios.

When considering the effectiveness of the system, it is important to differentiate between the chargeair temperature as an absolute value and charge-air temperature reduction as a function of the performance of the charge-air intake conditioner system performance. A higher $\eta_{\text {comp }}$ clearly gives a lower charge-air temperature but does not necessarily indicate the relative performance of the charge-air conditioning system. Accordingly, a system performance parameter $T_{\text {rel }}$ is defined as the charge-air temperature relative to that at $r_{\mathrm{ex}}=1.0$. Thus $T_{\text {rel }}$ is given by

$$
T_{\text {rel }}=T-T_{r_{\mathrm{ex}}=1.0}
$$

and is used to quantify the sensitivity of the overall system effectiveness to $\eta_{\text {comp }}$ (with $E_{\mathrm{IC}}$ and $\eta_{\text {ex }}$ held constant at 0.6).

Figure 8 shows the relationship between the system effectiveness parameter $T_{\text {rel }}$ and compressor isentropic efficiency $\eta_{\text {comp }}$ for the compressor pressure ratio $r_{\text {comp }}=4.0,8.0$, and 12.0. Generally, system effectiveness improves with $\eta_{\text {comp }}$. The rate of improvement increases with higher values of $r_{\text {comp }}$, but this

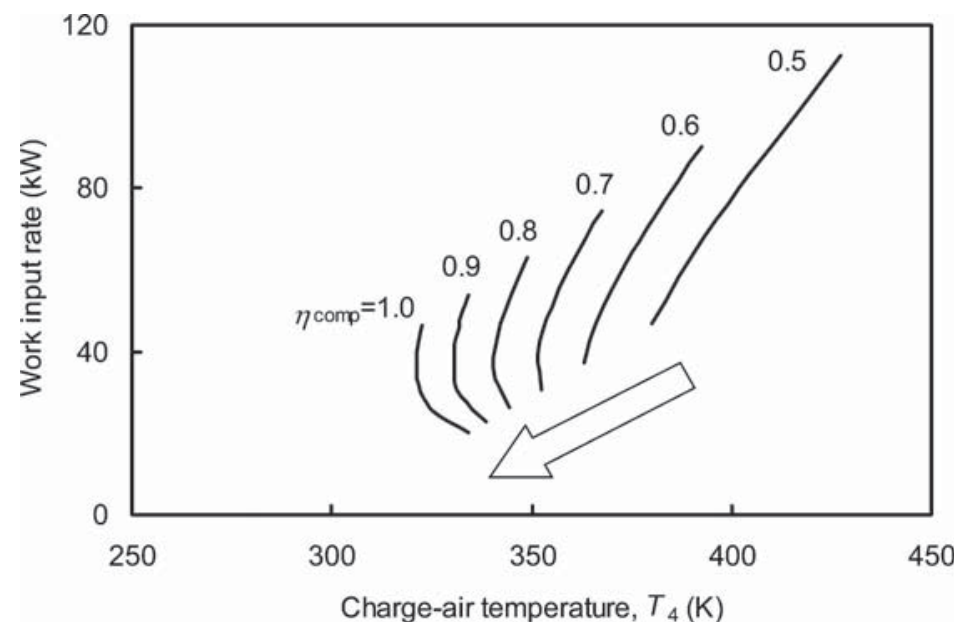

Fig. 7 Effect of compressor isentropic efficiency on the $\dot{W}-T$ characteristic $\left(E_{\mathrm{IC}}\right.$ and $\left.\eta_{\mathrm{ex}}=0.6\right)$ 


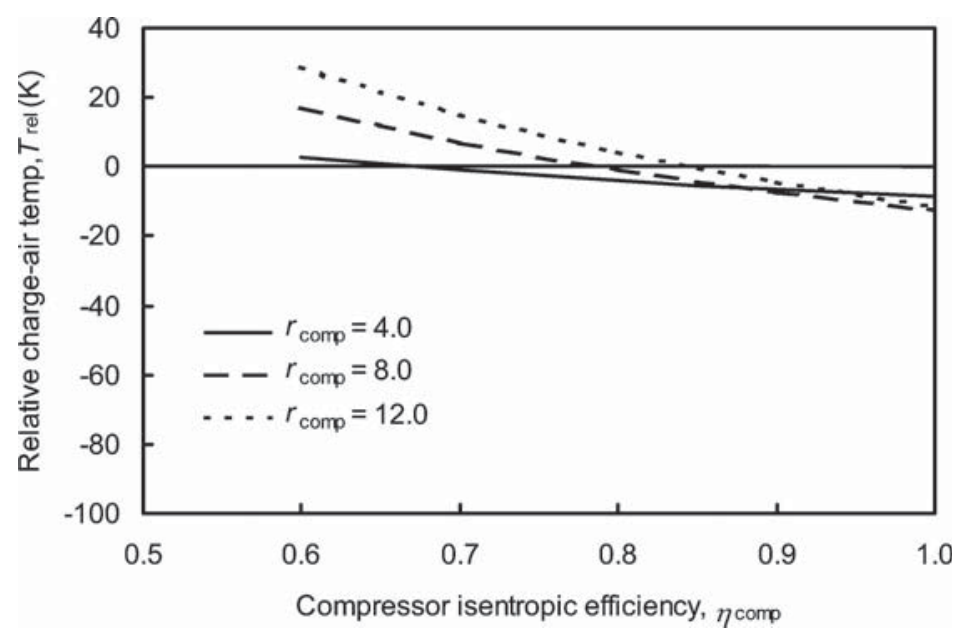

Fig. 8 Variation of system effectiveness with compressor isentropic efficiency $\left(E_{\mathrm{IC}}\right.$ and $\left.\eta_{\mathrm{ex}}=0.6\right)$

is of little practical use below $\eta_{\text {comp }}=0.9$ since $T_{\text {rel }}$ is either positive or no better than that at $r_{\text {comp }}=4.0$. For example, at $\eta_{\text {comp }} \leqslant 0.8$ the system effectiveness improves with reducing $r_{\text {comp }}$. There is, however, no benefit in reducing $r_{\text {comp }}$ below 4.0 as the limiting case of $r_{\text {ex }}=1.0$ will give a horizontal line at $T_{\text {rel }}=0$. This necessarily follows from the definition of $T_{\text {rel }}$.

Although a quantitative measure of system efficiency has not been defined, it can be seen from Fig. 7

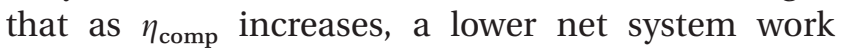
input rate is required for a given reduction in chargeair inlet temperature. From this observation, it can be deduced qualitatively that the efficiency of the system increases with $\eta_{\text {comp }}$.

\subsection{Intercooler effects}

Figure 9 shows the variation of system performance with intercooler effectiveness $E_{\mathrm{IC}}$ in the range 0.6-1.0. Compressor and expander isentropic efficiencies were held constant at 0.6 . While it is apparent from Figs 7 and 8 that a compressor with such a low isentropic efficiency will not necessarily be capable of delivering a charge-air temperature reduction, the constant efficiency values were chosen carefully in order to allow a valid comparison of the relative effects of the individual system components in section 6.4. While there is a general trend of reducing the charge-air temperature with increasing $E_{\mathrm{IC}}$, the effect on the net system work input rate depends upon $r_{\text {comp }}$, showing a work rate reduction of 19 per cent at $r_{\mathrm{ex}}=1.0$ and a work rate increase of 5 per cent at $r_{\text {comp }}=12.0$.

As with the analysis of compressor effects, it is necessary to use the performance parameter $T_{\text {rel }}$ to quantify the relationship between system effectiveness and intercooler effectiveness (see Fig. 10). Overall system effectiveness shows a high dependence upon intercooler effectiveness and the dependence rate increases with $r_{\text {comp. }}$. At intercooler effectiveness

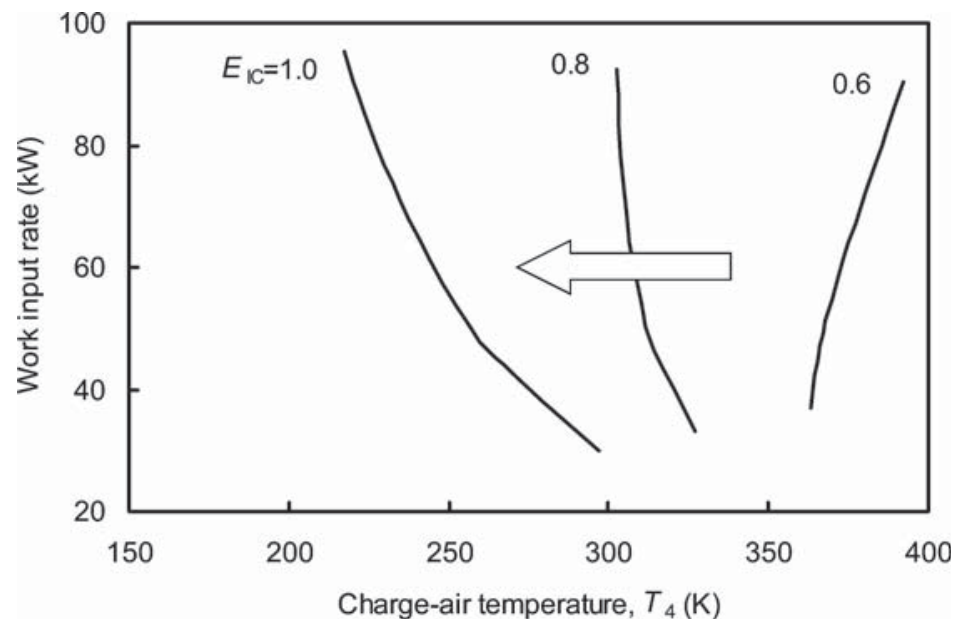

Fig. 9 Effect of intercooler effectiveness on the $\dot{W}-T$ characteristic ( $\eta_{\text {comp }}$ and $\eta_{\text {ex }}=0.6$ ) 


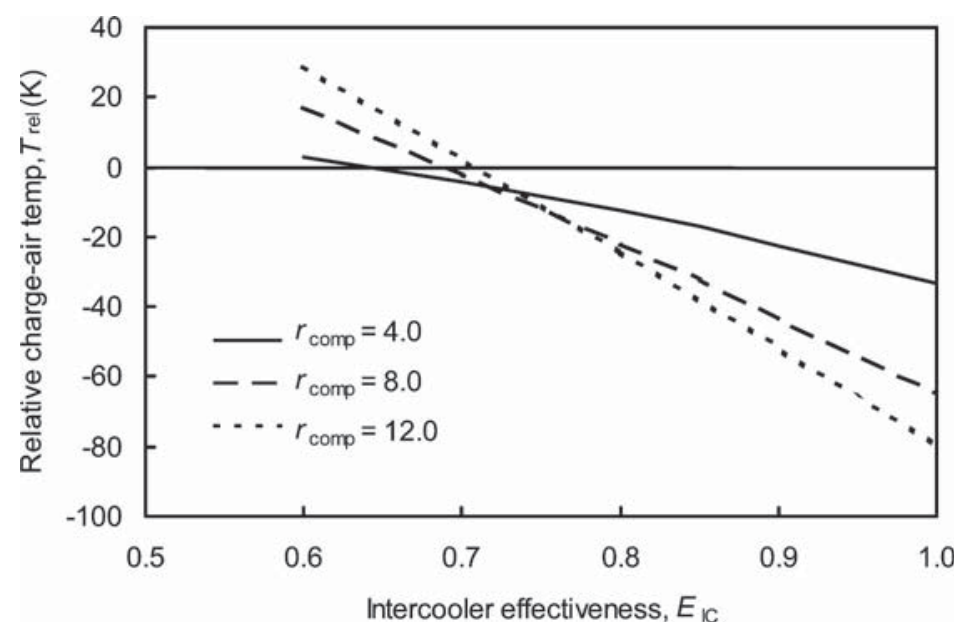

Fig. 10 Variation of system effectiveness with intercooler effectiveness ( $\eta_{\text {comp }}$ and $\left.\eta_{\text {ex }}=0.6\right)$

values greater than 0.7 there is significant potential to improve system effectiveness by maximizing $r_{\text {comp }}$.

As with the compressor analysis, it is clear from the curve shapes in Fig. 9 that as $E_{\mathrm{IC}}$ increases, a lower net system work input rate is required to achieve a given reduction in the charge-air inlet temperature. It follows therefore that system efficiency increases with $E_{\mathrm{IC}}$.

\subsection{Expander effects}

Figure 11 shows how the $\dot{W}-T$ curve varies with expander isentropic efficiency $\eta_{\text {ex }}$ at constant compressor isentropic efficiency $\eta_{\text {comp }}=0.6$ and constant intercooler effectiveness $E_{\mathrm{IC}}=0.6$. (The explanation for the choice of these constant values is as detailed in section 6.2.) As $\eta_{\text {ex }}$ is increased from 0.5 to 1.0 the $\dot{W}-T$ curve pivots around its start point at $r_{\mathrm{ex}}=1.0$ and the effectiveness of the system is clearly improved.
The curves all share the same origin, since $\eta_{\mathrm{ex}}$ has no effect at $r_{\mathrm{ex}}=1.0$, and in this case system effectiveness could be determined directly from the charge-air temperature. However, the system performance parameter $T_{\text {rel }}$ is retained for this analysis to allow a quantitative comparison between compressor, intercooler, and expander effects discussed later in section 6.4. The effectiveness of the system shows a strong dependence upon expander isentropic efficiency (see Fig. 12) and increasing dependence with an increasing compressor pressure ratio. At $\eta_{\mathrm{ex}} \geqslant 0.8$, there is potential for significant improvements in system effectiveness by maximizing $r_{\text {comp }}$. Figure 13 shows the combined effects of compressor and expander isentropic efficiency on system performance. As in the cases of both compressor and intercooler analyses, a qualitative examination of the curve shapes in Fig. 11 yields the result of system efficiency increasing with $\eta_{\mathrm{ex}}$.

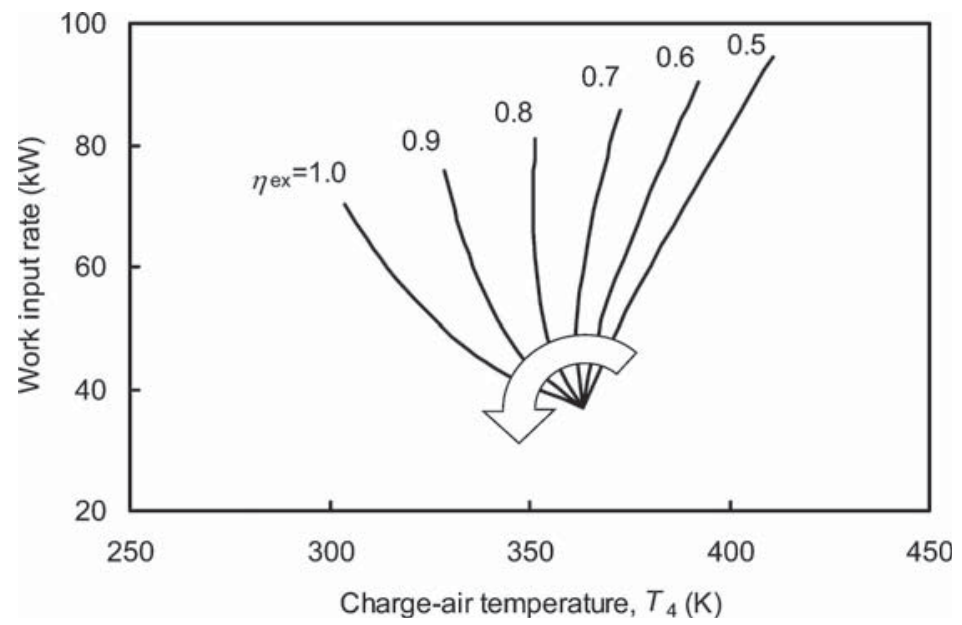

Fig. 11 Effect of expander isentropic efficiency on the $\dot{W}-T$ characteristic $\left(\eta_{\text {comp }}\right.$ and $\left.E_{\mathrm{IC}}=0.6\right)$ 


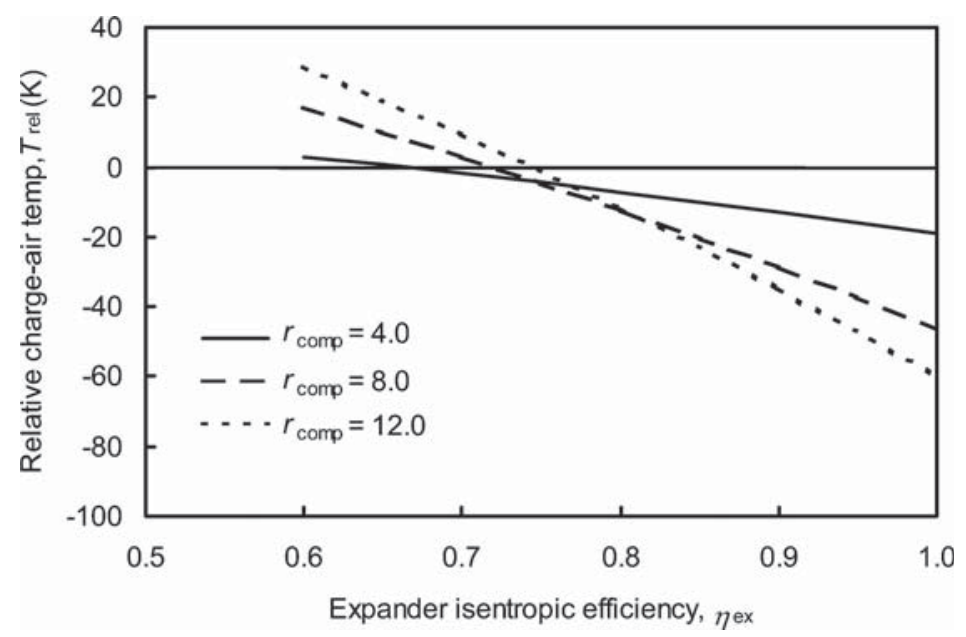

Fig. 12 Variation of system effectiveness with expander isentropic efficiency $\left(\eta_{\text {comp }}\right.$ and $\left.E_{\mathrm{IC}}=0.6\right)$

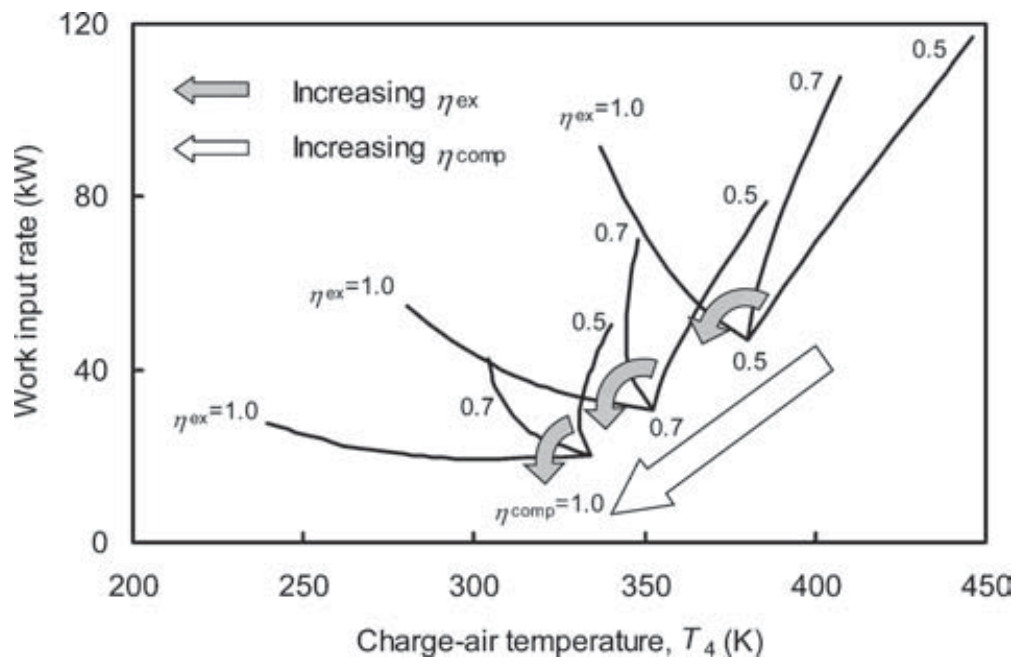

Fig. 13 Combined effects of compressor and expander isentropic efficiencies on the $\dot{W}-T$ characteristic $\left(E_{\mathrm{IC}}=0.6\right)$

\subsection{Comparison of compressor, intercooler, and expander effects}

Figure 14 shows the relative sensitivity of the system effectiveness to the efficiency of each of the components at $r_{\text {comp }}=4.0$. In each case, as the efficiency of the particular component was varied, the efficiencies of the other two components were held constant at 0.6. It is clear that system effectiveness is least sensitive to compressor isentropic efficiency. Its sensitivity to expander isentropic efficiency is greater by a factor of about 2 and its sensitivity to intercooler effectiveness is greater still, by a factor of about 3 . This result is particularly important since it indicates where time, effort, and money can be most effectively expended in the design and realization of a charge-air intake conditioner system.

From Figs 15 and 16 it can be seen that as $r_{\text {comp }}$ increases to 8.0 and then to 12.0 , the relative sensitivity of system effectiveness to $\eta_{\mathrm{ex}}$ increases. Figure 17 shows the system operating limit (at $r_{\text {comp }}=4.0$ and $E_{\mathrm{IC}}=0.6$ ) as a function of compressor and expander isentropic efficiencies. At values of low $\eta_{\text {comp }}$ and $\eta_{\text {ex }}$ the system cannot deliver a reduction in charge-air temperature. This is shown as the area of impractical operation. At higher compressor and expander efficiencies the system offers the potential for charge-air temperature reduction in the area of practical operation.

While it is possible, in some instances, to improve the effectiveness of the system by increasing $r_{\text {comp }}$, this does have the effect of adversely shifting the operating limit as the area of impractical operation increases. Figures 18 and 19, for example, show how the system reaches operating limits at $r_{\text {comp }}=8.0$ and 12.0 respectively. The shape of the limit line also changes, showing increased sensitivity to expander isentropic efficiency at higher pressure ratios. 


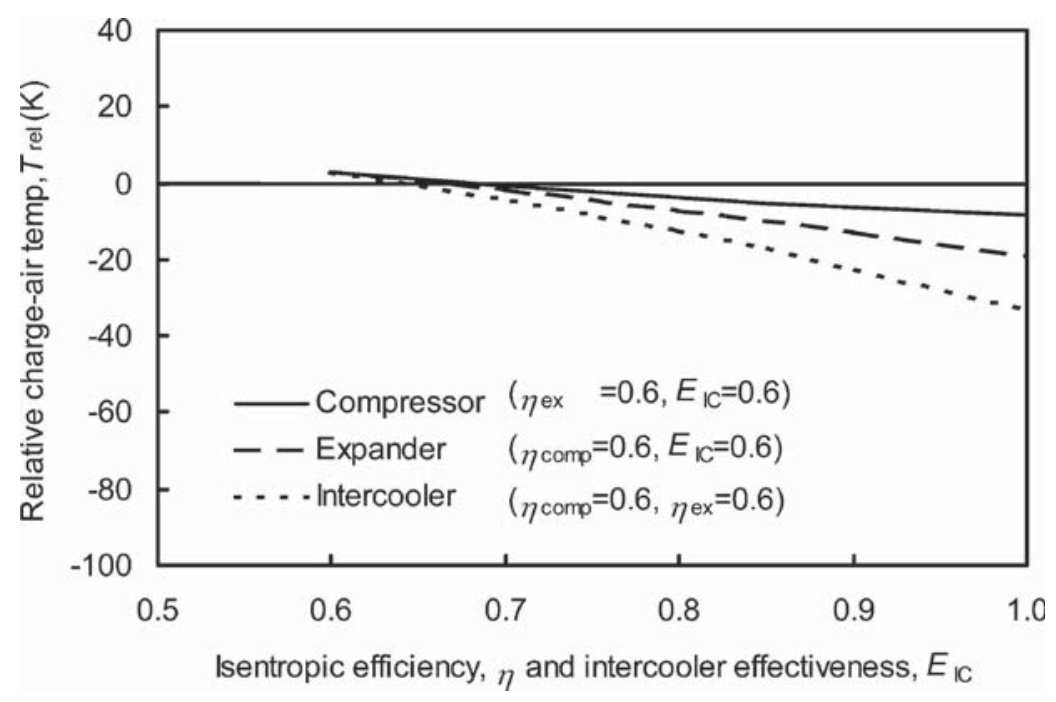

Fig. 14 Relative system sensitivity at $r_{\text {comp }}=4.0$

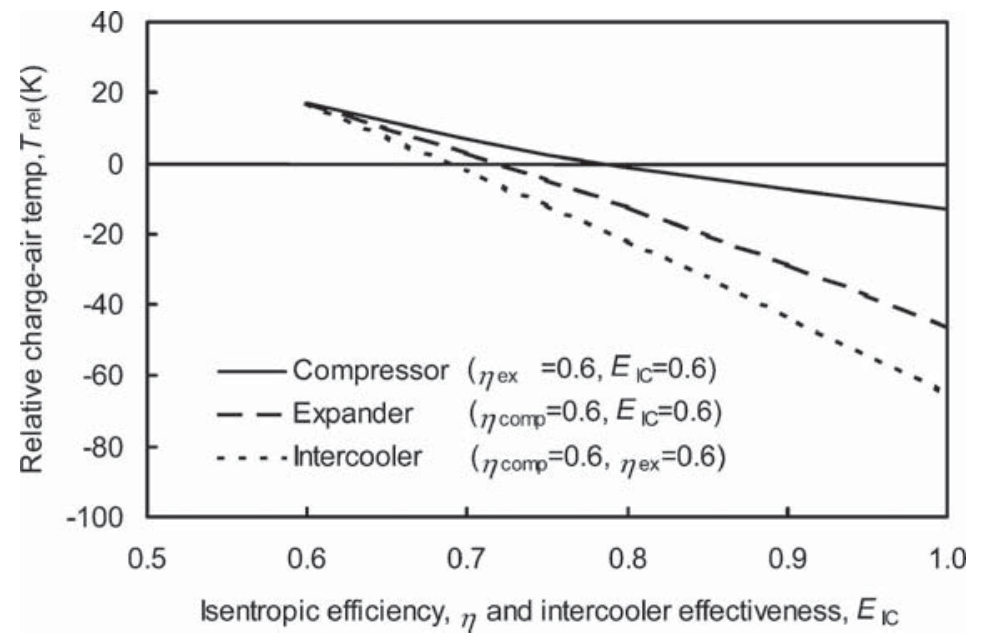

Fig. 15 Relative system sensitivity at $r_{\text {comp }}=8.0$

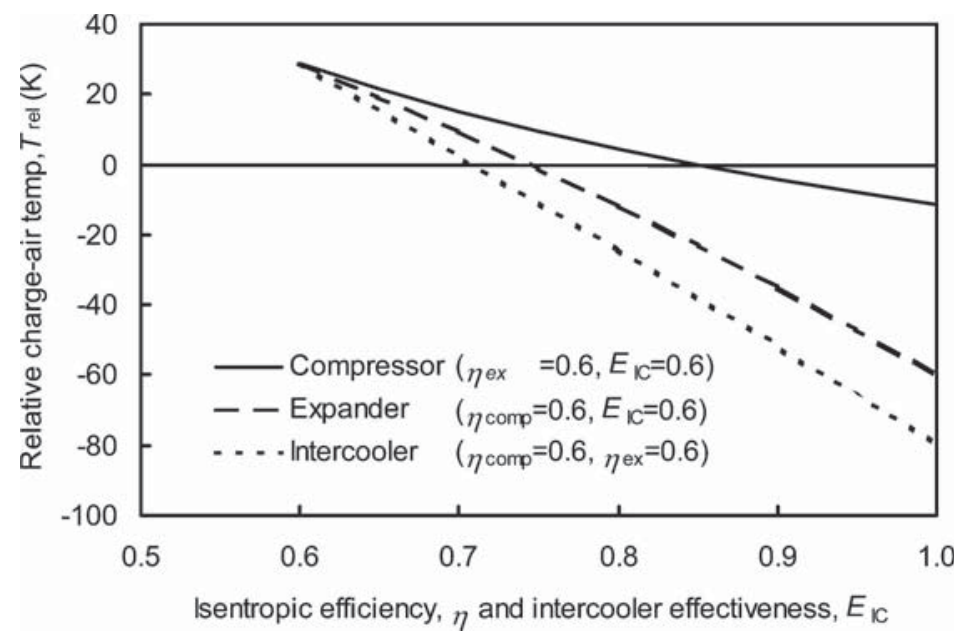

Fig. 16 Relative system sensitivity at $r_{\text {comp }}=12.0$ 


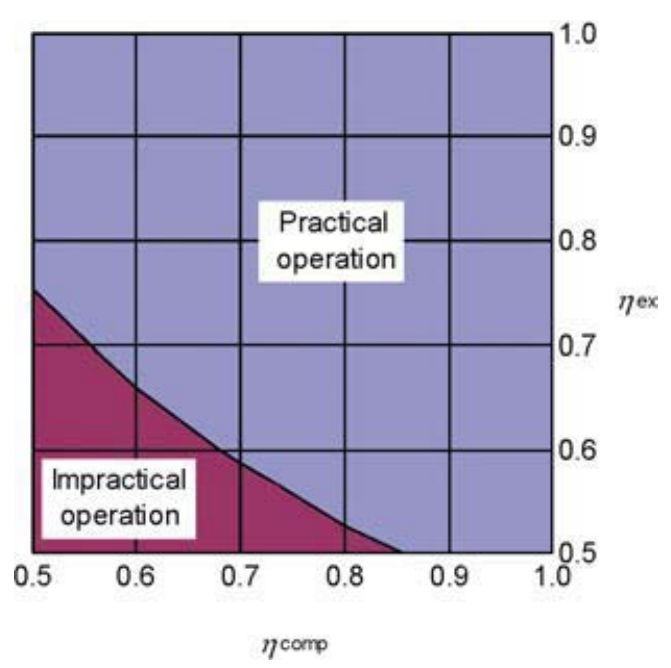

Fig. 17 System operating limit at $r_{\text {comp }}=4.0$ and $E_{\mathrm{IC}}=0.6$

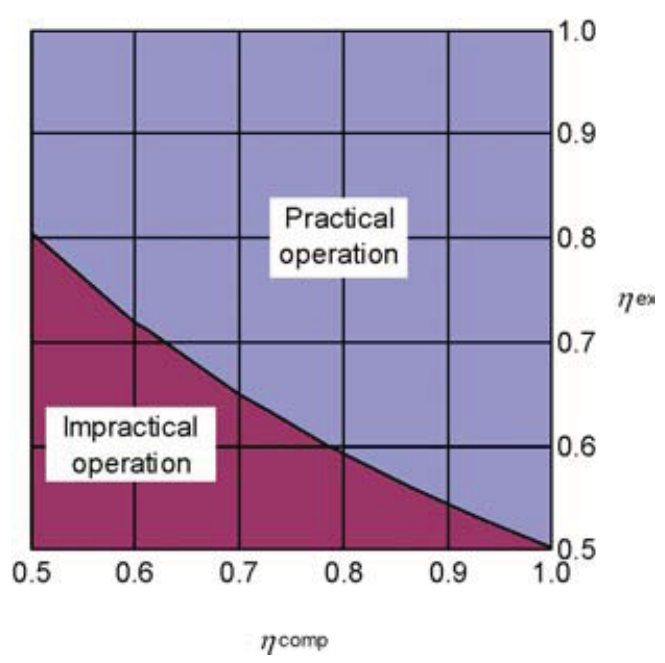

Fig. 18 System operating limit at $r_{\text {comp }}=8.0$ and $E_{\mathrm{IC}}=0.6$

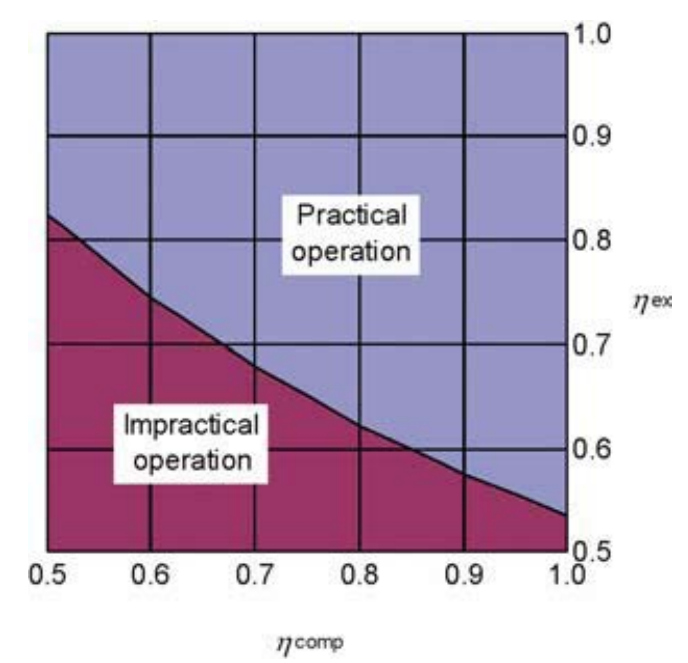

Fig. 19 System operating limit at $r_{\text {comp }}=12.0$ and $E_{\mathrm{IC}}=0.6$
Intercooler effectiveness $E_{\mathrm{IC}}$ also has an effect on the system operating limit and effectiveness sensitivity. Figures 20 and 21 show the operating maps for $E_{\mathrm{IC}}=0.6$ and 0.8 respectively. It can be seen that increasing the intercooler effectiveness significantly improves both the system operating limit and system effectiveness. It also has the effect of increasing the system's relative sensitivity to expander isentropic efficiency.

The system operating limit and sensitivity maps shown in Figs 17 to 21 are particularly relevant to the process of designing and engineering a chargeair intake conditioner system since they provide an immediate indication of the viability of a proposed specification. For example, Fig. 20 shows that for

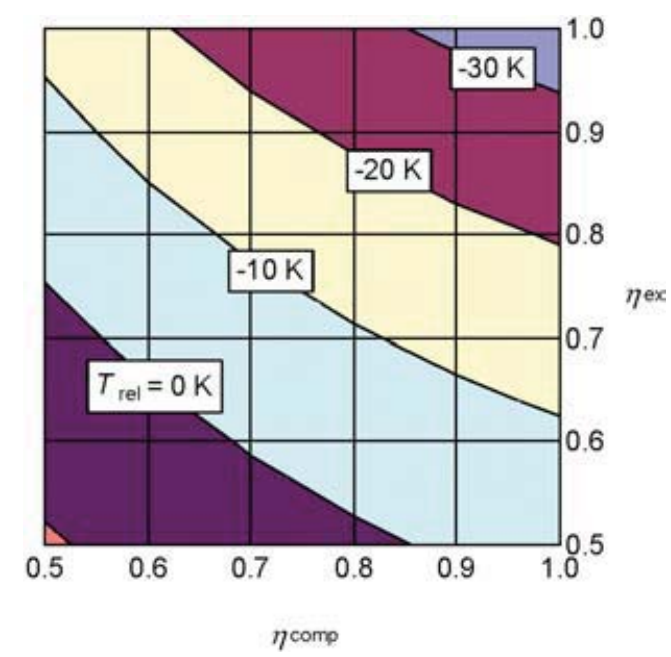

Fig. 20 System operating limit and effectiveness sensitivity at $r_{\text {comp }}=4.0$ and $E_{\mathrm{IC}}=0.6$

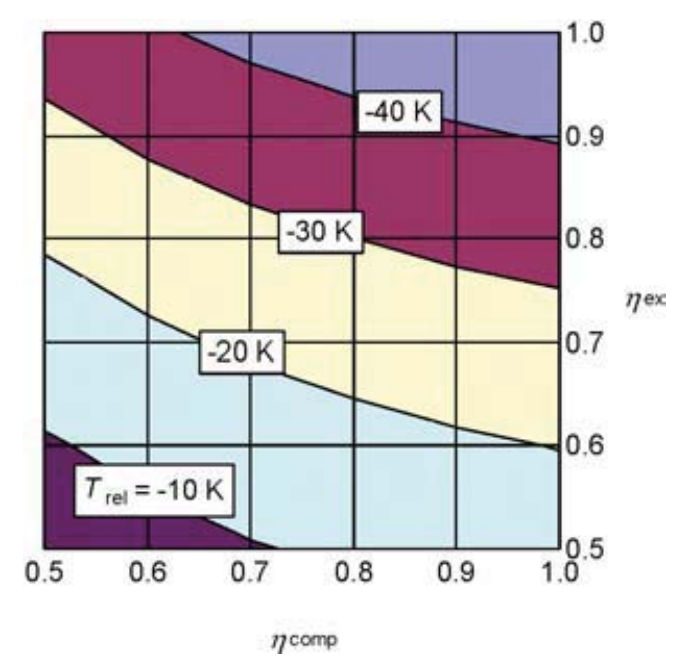

Fig. 21 System operating limit and effectiveness sensitivity at $r_{\text {comp }}=4.0$ and $E_{\mathrm{IC}}=0.8$ 
typical compressor and expander isentropic efficiency values of 0.6 (at $r_{\text {comp }}=4.0$ ) and an intercooler effectiveness of 0.6 , the system is not practical since it cannot deliver a reduction in the charge-air temperature. However, increasing intercooler effectiveness to 0.8 has a significant effect on the performance of the overall system and gives a potential reduction in the charge-air temperature of between 10 and $20 \mathrm{~K}$ (see Fig. 21).

\section{CONCLUSIONS}

This analysis has yielded a number of new useful findings that are summarized as follows:

1. A first law thermodynamic model has been developed to characterize the performance of an internal combustion (IC) engine charge-air intake conditioner system proposed by Turner et al. [4]. The system comprises a compressor, an intercooler, and an expander, and achieves both increased charge-air density and reduced chargeair temperature (by means of irreversible heat transfer from the intercooler and adiabatic expansion across the expander). The model has been validated against measured results [4] and has been used to determine the relationship between charge-air temperature $T$ and work rate input requirement $\dot{W}$ at constant charge-air density and mass flowrate.

2. A characterization of system performance has been developed using the $\dot{W}-T$ plot, and this has shown that there are limits to the performance of the system imposed by the individual component efficiencies and also by the pressure ratio $\left(r_{\text {comp }}\right.$ and $\left.r_{\text {ex }}\right)$ at which the system operates.

3. A system performance parameter, the relative temperature $\left(T_{\text {rel }}\right)$, has been used to define the effectiveness of the system as a function of component efficiency. This analysis has shown that system effectiveness is least sensitive to compressor isentropic efficiency. Its sensitivity to expander isentropic efficiency is greater by a factor of about two and its sensitivity to intercooler effectiveness is greater still by a factor of about three. The effects of all component efficiencies increase with the pressure ratio at which the system operates.

4. A parametric study has shown that for given intercooler effectiveness and system pressure ratio, the system operating limit can be determined as a function of compressor and expander isentropic efficiencies. This operating limit shows increased sensitivity to expander isentropic efficiency at higher system pressure ratios and higher intercooler effectiveness. Although this analysis is performed at a constant charge-air density and mass flowrate, it is particularly valuable as a test of the viability of a proposed charge-air intake conditioner system. A system that fails this test will necessarily fail to achieve its objective performance at constant engine b.m.e.p. since, at any given engine speed, a higher charge-air density and mass flowrate will be required to produce the additional work to drive the system. This will have the effect of an adverse (upward) shift of the $\dot{W}-T$ characteristic, with the result that the charge-air temperature cannot be lower than that of the constant density and mass flowrate analysis. It is not, however, valid to apply the corollary of this argument to infer that if a system passes this first test it will also be effective at constant engine brake power. In such a case it would be necessary to carry out engine cycle simulations to determine system work input requirements at constant fullload b.m.e.p. from which corresponding system operating limits could be determined. This is the subject of the authors' ongoing research.

\section{ACKNOWLEDGEMENTS}

The authors wish to thank the Royal Academy of Engineering and Perkins Engines for their financial support of the second author. They also thank Group Lotus plc and Opcon Autorotor AB for the use of experimental data.

\section{REFERENCES}

1 Wood, S. P. and Bloomfield, J. H. Clean power - Lotus 2.2 Lt chargecooled engine. SAE paper 900269, 1990.

2 Drangel, H. and Bergsten, L. The new SAAB SVC engine - an interaction of variable compression ratio, high pressure supercharging and downsizing for considerably reduced fuel consumption. In Aachen Colloquium, 2000.

3 Douaud, A. M. and Eyzat, P. Four-octane-number method for predicting the anti-knock behaviour of fuels and engines. SAE paper 780080, 1978.

4 Turner, J. W. G., Pearson, R. J., Bassett, M. D., and Oscarsson, J. Performance and fuel economy enhancement of pressure charged SI engines through turbo expansion - an initial study. SAE paper 2003-01-0401, 2003.

5 Cengel, Y. A. and Boles, M. A. Thermodynamics: An Engineering Approach, 3rd edition, 1998 (McGrawHill, Maidenhead). 
6 Eastop, T. D. and McKonkey, A. Applied Thermodynamics for Engineering Technologists, 5th edition, 1993 (Longman, Oxford).

\section{APPENDIX}

\section{Notation}

a polynomial coefficient

A flow area $\left(\mathrm{m}^{2}\right)$

b.m.e.p. brake mean effective pressure $(\mathrm{Pa})$

b.s.f.c. brake specific fuel consumption

(g/kW h)

$c_{p} \quad$ constant pressure specific heat

capacity $(\mathrm{J} / \mathrm{kg} \mathrm{K})$

$c_{v} \quad$ constant volume specific heat capacity

( $/ \mathrm{kg} \mathrm{K}$ )

COP coefficient of performance

$E \quad$ total energy (J) and intercooler

effectiveness

$h \quad$ specific enthalpy $(\mathrm{J} / \mathrm{kg})$

IC internal combustion

$k \quad$ intercooler pressure drop constant

$m \quad$ mass (kg)

$M \quad$ molar mass $(\mathrm{kg} / \mathrm{kmol})$

$p \quad$ pressure $(\mathrm{Pa})$

$q \quad$ specific heat transfer $(\mathrm{J} / \mathrm{kg})$

Q heat transfer (J)

$r \quad$ pressure ratio

$R \quad$ gas constant $(\mathrm{J} / \mathrm{kg} \mathrm{K})$

$s \quad$ specific entropy (J/kg K)

SFEE steady flow energy equation

SI spark ignition

T temperature (K) $v$

$w$

W

$\gamma$

$\Delta$

$\eta$

$\rho$

v

\section{Subscripts}

a
atm
comp
ex
i
in
I-IV
IC
out
ref
rel
sink
sys
0
1
2
3
4

\section{Superscripts}

- (dot) derivative with respect to time $\left(\mathrm{s}^{-1}\right)$

' (prime) ideal process

specific volume $\left(\mathrm{m}^{3} / \mathrm{kg}\right)$

specific work $(\mathrm{J} / \mathrm{kg})$

work $(J)$

ratio of specific heats

finite change in quantity

efficiency

density $\left(\mathrm{kg} / \mathrm{m}^{3}\right)$

velocity $(\mathrm{m} / \mathrm{s})$

actual

atmospheric

compressor

expander

isentropic

inlet

polynomial coefficient subscripts

intercooler

outlet

reference

relative to condition at $r_{\mathrm{ex}}=1.0$

sink

system

stagnation

compressor inlet

compressor outlet/intercooler inlet

expander inlet/intercooler outlet

expander outlet 